\title{
Left Hepatic Duct
}

National Cancer Institute

\section{Source}

National Cancer Institute. Left Hepatic Duct. NCI Thesaurus. Code C32960.

The duct that drains bile from the left lobe of the liver into the common hepatic duct. 